\title{
Effect of Copper(II) Ions on Corrosion Resistance of Al-Zn Coated 5052 Aluminum Alloy in Seawater
}

\author{
Guofeng $\mathrm{Lv}^{1, *}$, Yanming Xia ${ }^{2}$, Xiong Chen ${ }^{1}$, Zhao Liu ${ }^{1}$, Fang Zhuang ${ }^{1}$, Zhiming Gao ${ }^{2, *}$ \\ ${ }^{1}$ Petrochina Jiangsu LNG Company Limited, Nantong, 226001, China \\ ${ }^{2}$ Engineering Research Center of Composite and Functional Materials, School of Materials Science \\ and Engineering, Tianjin University, Tianjin, 300072, China \\ *E-mail: 1vgf169@petrochina.com.cn, gaozhiming@tju.edu.cn
}

Received: 5 May 2021 / Accepted: 27 July 2021 / Published: 10 September 2021

The corrosion resistance of the composite anti-corrosion coating formed by an aluminum-zinc coating and epoxy sealer on the surface of an open rack vaporizer (ORV) in seawater was investigated at different copper ion $\left(\mathrm{Cu}^{2+}\right)$ concentrations. The surface microstructure of the coating was characterized by ultrafield 3D observation, SEM and energy spectrum analysis (EDS). The sealer was found to be effective in shielding the coating surface and significantly reduced the corrosion rate of the coating. A dissolution process of the passive film on the coating surface is evident from the potentiodynamic polarization curves and surface morphology. Local corrosion occurs on the coating surface, and the number and area of surface corrosion pits increase with the concentration of copper in solution, indicating a decrease of the corrosion resistance of the coating. Weight loss of the samples increases from $4.5 \mathrm{mg}$ to $5.4 \mathrm{mg}$ after a 32 days immersion, and the damage of copper ions on the coating originates from weak positions of the surface. The electrochemical corrosion behavior of the coating was investigated by dynamic potential polarization and electrochemical impedance spectroscopy (EIS), with a positive effect found after a short immersion period in a solution with copper ion concentration lower than $5 \mathrm{ug} / \mathrm{L}$, with this effect not evident at higher copper concentrations.

Keywords: Copper ions, composite coating, corrosion morphology, potentiodynamic polarization;, electrochemical impedance spectroscopy

\section{FULL TEXT}

(C) 2021 The Authors. Published by ESG (www.electrochemsci.org). This article is an open access article distributed under the terms and conditions of the Creative Commons Attribution license (http://creativecommons.org/licenses/by/4.0/). 